\title{
The Nature of Reflective Practice and Emotional Intelligence in Tutorial Settings
}

\author{
Gobinder Singh Gill ${ }^{1}$ \\ ${ }^{1}$ Sport, Uniformed Services \& Travel, Birmingham Metropolitan College, West Midlands, UK \\ Correspondence: Gobinder Singh Gill, Sport, Uniformed Services \& Travel, Birmingham Metropolitan College, \\ West Midlands, UK. Tel: 44-788-578-1761. E-mail: gillgk@yahoo.com
}

Received: June 9, 2013

Accepted: December 17, 2013 Online Published: February 19, 2014

doi:10.5539/jel.v3n1p86

URL: http://dx.doi.org/10.5539/jel.v3n1p86

\begin{abstract}
The purpose of this paper was to assess the nature of reflective practice and emotional intelligence in tutorial settings. Following the completion of a self-report measure of emotional intelligence, practitioners incorporated a model of reflective practice into their tutorial sessions. Practitioners were instructed to utilise reflective practice and emotional intelligence with their students during weekly tutorials for three weeks. It was postulated that a relationship between reflective practice and emotional intelligence would emerge. Results indicated that reflective practice enabled practitioners to enhance their emotional intelligence skills, specifically self-awareness. In addition, focus group interviews identified that practitioners adopted a range of strategies to increase their own emotional intelligence skills and improve reflective practice. Considerations for future investigations would include a longitudinal design that would use semi-structured interviews to enable deeper understanding of reflective practice and emotional intelligence.
\end{abstract}

Keywords: reflective, emotions, practitioners, learners, regulation

\section{Introduction}

Green (2001) contends that the tutorial system is an integral part of Further Education as it provides opportunities for practitioners to support students with assessments, exams, mentoring and discipline. It could be suggested therefore that practitioners provide support on personal and emotional levels. It could therefore be suggested that the tutorial system requires practitioners to support output which engineers thought and interpretation. Taken together the tutorial system facilitates in the understanding of strengths and identifies areas to improve. Facilitation can occur through many avenues of which reflective practice (Gibbs, 1988) is a popular choice. Knowles, Gilbourne and Tomlinson (2007) contend that reflective practice is the exploration of thoughts, feelings and actions. Through reflective practice and critical interpretation understanding and learning can be formed. Based on this supposition it could be suggested that the tutorial system is the fulcrum from which all other learning evolves.

Research evidence quantifies the effectiveness of reflective practice because of its opportunity to support individuals and groups (see, education, Farrell, 2008; Lee, 2005; health, Ekebergh, 2007; sport, Knowles et al., 2007). One benefit of reflective practice resonates with its impact when working in groups. For example, group work can lead practitioners to develop practices that include analysing work and designing strategies to maintain improvement. Given that student engagement is formed through dealing with interpersonal relationships, different situational perspectives and the ability to make decisions, practitioners can teach and support students (Farrell, 2008). Therefore, reflective practice can be postulated to benefit both practitioners and students in tutorial settings.

Through reflective practice a range of scenarios could be introduced by practitioners to enhance reflective practice during tutorials. One popular scenario that could be utilised is time management. In consideration of time-management it would be pertinent to explain the Gibbs (1998) six-stage model. Stage 1 of the model relates to description from which practitioners, working with students, can form a profile of assessment deadlines. Following identification of this profile the practitioner could task students to explain their feelings (stage 2) on how they time manage to meet deadlines. Having formed their feelings students could be tasked to evaluate their strengths and weaknesses of the process (stage 3). Following this evaluation, students could be encouraged to develop skills related to problem solving and independent thinking when managing their time (stage 4). Further 
opportunities are then afforded to assess the different requirements and needs that would support the process (stage 5). From this, an action plan (stage 6) is formed to support the process of time management.

Arguably, reflective practice allows practitioners to become aware of student emotions, recognise individual needs and develop strategies to regulate thinking. These skills are important, as practitioners must take care of student academic requirements and overall wellbeing. In addition, it is also important to increase student ability to problem solve and promote independent thinking. Therefore, practitioners are required to employ emotive regulatory practices. A key construct that can align closely with emotive regulatory practices is emotional intelligence. Emotional intelligence has been defined as "the ability to monitor one's own and others' feelings and emotion, to discriminate among them and to use this information to guide one's thinking and actions" (Salovey \& Mayer, 1990, p. 189).

Considerable research has highlighted the effectiveness of emotional intelligence (e.g., Petrides, Furnham, \& Frederickson, 2004; Salovey \& Mayer, 1990; Van Rooy \& Viswesvaran (2004); Zeidner, Matthews, \& Roberts, 2004). One recent research example has found co-existence between emotional intelligence and coaching efficacy (Thelwell, Lane, Weston \& Greenlees, 2008). Arguably the work of coaches aligns to that of practitioners within education. For example, practitioners in coaching and education need to be self-aware of their own emotions in order to help support and regulate emotions of performers they work and guide. A number of emotional intelligence models (Salovey \& Mayer, 1990; Petrides et al., 2004) have been proposed, however this investigation will focus on the Goleman (2004) model, as it is more cognizant to educational tutorial practices. In making the supposition that the Goleman (2004) model is purposeful to tutorial settings, it would be pertinent to advocate its use. Given the postulation provided it would be purposeful to explain possible relationships between reflective practice and key components of emotional intelligence related to the Goleman (2004) model within tutorial settings.

The first key aspect of emotional intelligence relates to self-awareness, which alludes to "the ability to recognize and understand your moods, emotions, and drives, as well as their effect on others" (Goleman, 2004, p. 88). Self-awareness is important because awareness of own emotions should regulate thinking processes. In exploring life skills, tutorials now contain a range of material related to wellbeing and mental health. Therefore, to raise self-awareness practitioners could for example, introduce a video of mental health. Arguably, with student engagement it could be postulated that awareness could be raised as reflective practice is formed through interpretation of the mental health video. Recent research found that graduate students benefitted from developing their own self-awareness to help support them when dealing with younger pupils (Perez, 2011). Therefore in postulation, reflective practice could stimulate interpretation of thought from which actions are formed that build self-awareness.

A second aspect of the emotional intelligence model relates to self-regulation, which is defined as "the ability to control or redirect disruptive impulses and moods; the tendency to suspend judgment to think before acting" (Goleman, 2004, p. 88). Theoretically, practitioners who report high levels of emotional intelligence are more likely to self-regulate their emotions than those low in emotional intelligence (Salovey \& Mayer, 1990). Aligned to self-regulation is that reflective practice is concerned with thinking about emotions and to act accordingly (Farrell, 2008). One aspect that can relate to regulating emotions concerns the management of assessments. Tutorials provide practitioners opportunities to teach students how to manage assessments within their subject areas. It is imperative for practitioners to regulate emotions by providing students with opportunities to manage assessments. Therefore, it could be postulated that practitioners could utilise the Gibbs (1988) reflective practice model to allow students to identify their feelings and action plan on a regular basis. Through performing these tasks it could be postulated that students will invariably build increased mechanisms that make them self-regulate their emotions in order to cope with pressure of assessment completion. The ability to self-regulate is supportive to both practitioners and students because it provides a vacuum from which understanding of situations and awareness of how these occur in the first place are formed.

The tutorial system is designed for practitioners to develop strategies that increase or maintain motivation levels. Motivation, arguably a key characteristic for practitioners forms the third area of the Goleman (2004) model. Motivation is the inner self-drive and dedication to meet challenges. The tutorial system is designed for practitioners to develop strategies that increase or maintain motivation levels. Goal setting was one such strategy investigated by Cheung (2004) as a motivational tool to enhance student learning. It was found that goals alone were not effective, but that the use of process goals aided by action plans would enhance motivation levels. It could be argued that an important role of a practitioner is to continuously raise motivation levels of their students in order to keep them on track. One example of increasing motivation would be to propose the maintenance of 
journal logs that would facilitate progress. Implementing the Gibbs (1988) model for this purpose is useful because it provides the practitioner with ample opportunities to allow students to action plan and set continuous targets. Given that theory proposes for process goals to be set (Locke \& Latham, 1990) practitioners could set up action plans that are broken down into shorter specific targets each term. Indeed, it has been suggested that high achievers resort to setting goals more consistently than low achievers (Zimmerman \& Martinez-Pons, 1986).

Empathy is important in tutorials because it allows the practitioner to support and guide students in both academic and personal lifestyle issues. Empathy is related to having the ability to understand other people and can be considered as fundamental for tutorials. Theoretically, practitioners high in emotional intelligence are more likely to have increased empathy (Salovey \& Mayer, 1990). Enhancing empathy levels leads to effective working relationships and can increase productivity (Gentry, Weber, \& Sadri, 2007). Therefore, practitioners should attempt to guide students in an attempt to increase their empathy levels. During tutorials it could be proposed that empathy could be increased through developing role-play scenarios. Developing these scenarios will arguably enable students to work in groups and increase their ability to critically interpret events.

A final area of the Goleman (2004) model relates to relationship management and is the consequence of developing skills and strategies in managing others. Relationship management within the tutorial system is important because the constant need to deal with issues. As students are readily challenged and the tutorial system provides the fulcrum from which practitioners encourage increased performance levels, managing these relationships becomes imperative. To enhance this process, it could be argued that a great deal of objectivity and purpose is required by practitioners. Developing group activities that students engage with and report back in their groups would be useful for students to understand each role and manage accordingly. Relationship management and reflective practice can align because thinking and acting allows practitioners to develop future actions that can lead to improved performance.

The purpose of this research was to examine the nature of reflective practice and emotional intelligence in tutorial settings. Given that the tutorial system is directive to learner needs the use of reflective practice and emotional intelligence provides practitioners opportunities to support and guide students. A consideration of this research was to assess emotional intelligence and reflective practice in relation to gauge potential relationships with different age categories. Three main objectives relative to this research were, does the use of reflective practice help enhance emotional intelligence levels? do practitioners who already exhibit high levels of emotional intelligence engage in increased use of reflective practice? and what implications can the use of reflective practice and emotional intelligence have on tutorial settings in education?

\section{Method}

\subsection{Participants}

94 participants (Age: $\mathrm{M}=39.8$ years, $\mathrm{SD}=2.92)$ volunteered their consent. Age ranges were $(20-30 \mathrm{n}=13)(31-40$ $\mathrm{n}=36)(41-50 \mathrm{n}=27)(51-60 \mathrm{n}=13)(61+\mathrm{n}=5)$. Participants teaching experience amounted to $(0-5$ years $\mathrm{n}=5)(6-10$ years $n=17)(11-15$ years $n=19)(16-20$ years $n=28)(21-24$ years $n=18)(25+$ years $n=7)$ and were either main grade lecturers, involved in middle management or senior management. All participants taking part in this investigation were personal tutors to a group of learners on level 3 courses.

Participants were invited to take part in the study through the College email and SharePoint systems where announcements were made. This was facilitated through designated staff development sessions. To facilitate the focus group interviews it was decided to choose 10 members of staff from the 94 who had volunteered consent to take part in the study. Therefore, the researcher selected the first number in ten (e.g., 1, 11, 21, 31, 41, 51) and continued this until 10 participants were selected. Once selected there was initial email contact and where practitioners on the list were not available the next number on the list was contacted. When 10 practitioners volunteered their consent a time and meeting point was arranged.

\subsection{Measures}

Reflective practice. The Gibbs (1988) 6 stage model of reflective practice was implemented within this study. Each stage of the model is a step to the next stage. For example, the first stage relates to description (what happened?), stage two is about feelings (what were you feeling/thinking?), stage three relates to evaluation (what was good/bad about the experience?) stage four identifies with analysis (what sense can you make of the situation?), stage five offers a conclusion (what else could I have done?) and finally stage six is based on forming an action plan (if it arose again, what would I do?).

This model of reflective practice was presented to practitioners during a staff development session. To raise awareness of reflection within the tutorial system participants were provided with case scenarios that are typical 
of a normal college day. Having discussed these scenarios in groups, practitioners were instructed to form action plans and identify future recommendations. Following the staff development session all participants were instructed to develop reflective practice during tutorials for three weeks.

Emotional Intelligence. The Practical EQ Emotional Intelligence (see appendix, A) was utilised for the purpose of this study. The Practical EQ is a self-report measure that offers opportunities for assessing participants' emotional intelligence and self-perceptions. The Emotional Intelligence Self-Assessment Questionnaire is based on the five-competency model proposed by Daniel Goleman (2004) that identifies 5 core domains of self-awareness, self-management, motivation, empathy, and relationship management. Each section has 5 questions with score ranges from 0 (Almost never) - 5 (Almost always). In total there are 25 questions of which 9 are reversed scores. Examples of questions included, "I can explain my actions," (self-awareness), "I am prone to outbursts of anger, "(self-management), "I feel excited when I think of my goals," (motivation), "I find it easy to read others peoples emotions,"(empathy) and "I encounter difficult people," (relationship management). The self-report nature of the Practical EQ measure of emotional intelligence allows opportunity for participants to report the effects of emotions on everyday life as self-perception allows for change (Petrides, Furnham \& Frederickson., 2004; Petrides, Sangareau, Furnham \& Frederickson, 2006). Both measures utilised within this investigation were related to collecting quantitative and qualitative data. As the measures of emotional intelligence that was utilised for this investigation was a free self-assessment and therefore carries limited scientific validity. However, it is designed to make participants to think about their own emotional intelligence in order for that to be improved.

\subsection{Procedures}

Five key points underpinned this investigation which was structured but flexible in nature. Key point 1 presented knowledge of the two key areas (reflective practice and emotional intelligence). Key point 2 utilised the reflective practice model during a 3 -week tutorial session. Key point 3 was based on completion of the emotional intelligence questionnaire on two separate occasions. Key point 4 related to the focus group interviews (see appendix B) in which 10 volunteer practitioners consented to their participation. Key point 5 was the plenary session from which feedback relating to the whole process was taken.

\subsection{Data Analysis}

To form appropriate analysis all data was inputted onto an Excel spread sheet. Charts and tables were created to answer the stipulated research questions. A mixed method approach (Greene, 2007) using quantitative and qualitative methods was implemented to support this investigation.

\section{Results}

Table 1. Percentage increase of each domain on completion of the Practical Emotional Intelligence Self-Report Questionnaire over two testing periods

\begin{tabular}{ll}
\hline Goleman (2004) Sub-Domain Model Scores & Percentage Increase between each testing period \\
\hline Self-Awareness & $15.25 \%$ \\
Self-Regulation & $26 \%$ \\
Motivation & $14 \%$ \\
Empathy & $15 \%$ \\
Relationship Management & $12.5 \%$ \\
Average Percentage Increase & 16.55 \\
\hline
\end{tabular}




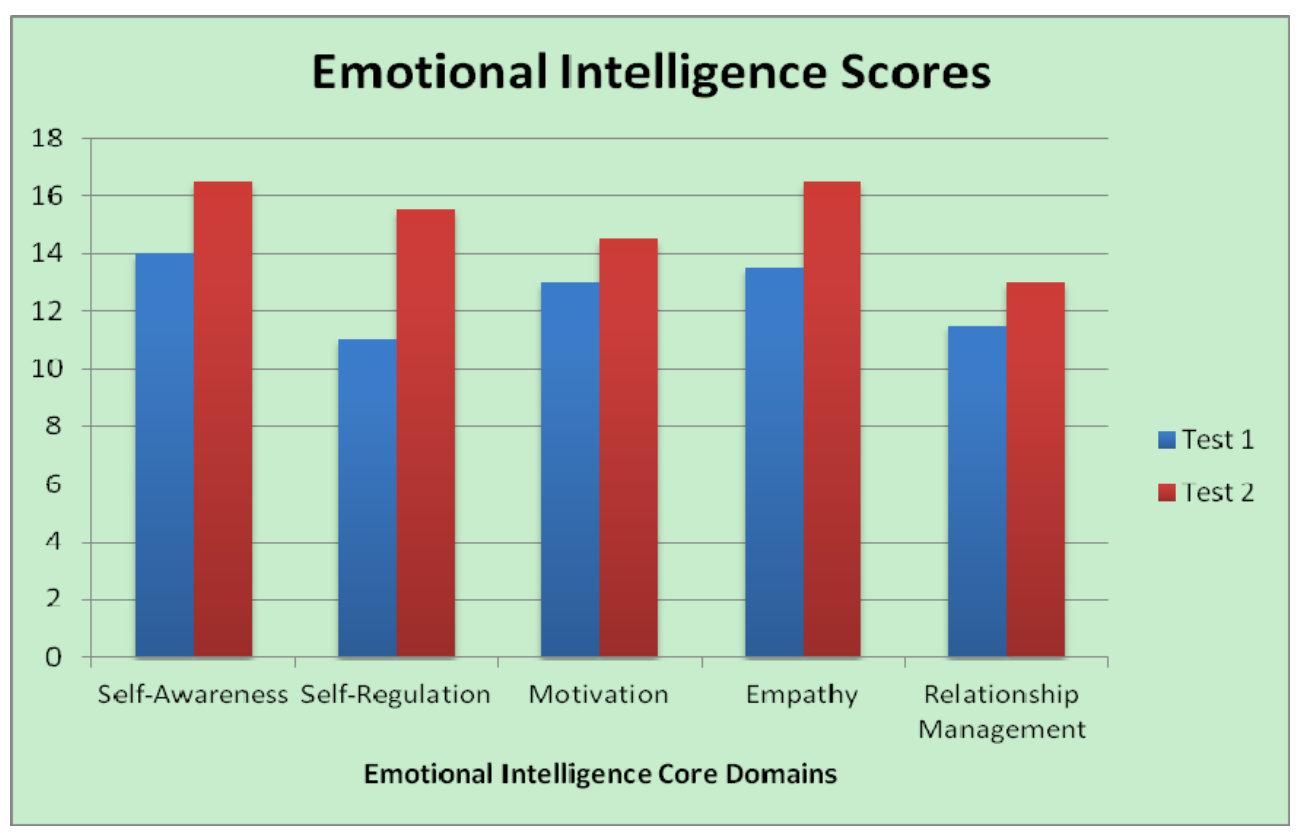

Figure 1. Data illustrating an increase in emotional intelligence across all domains following the three-week testing period

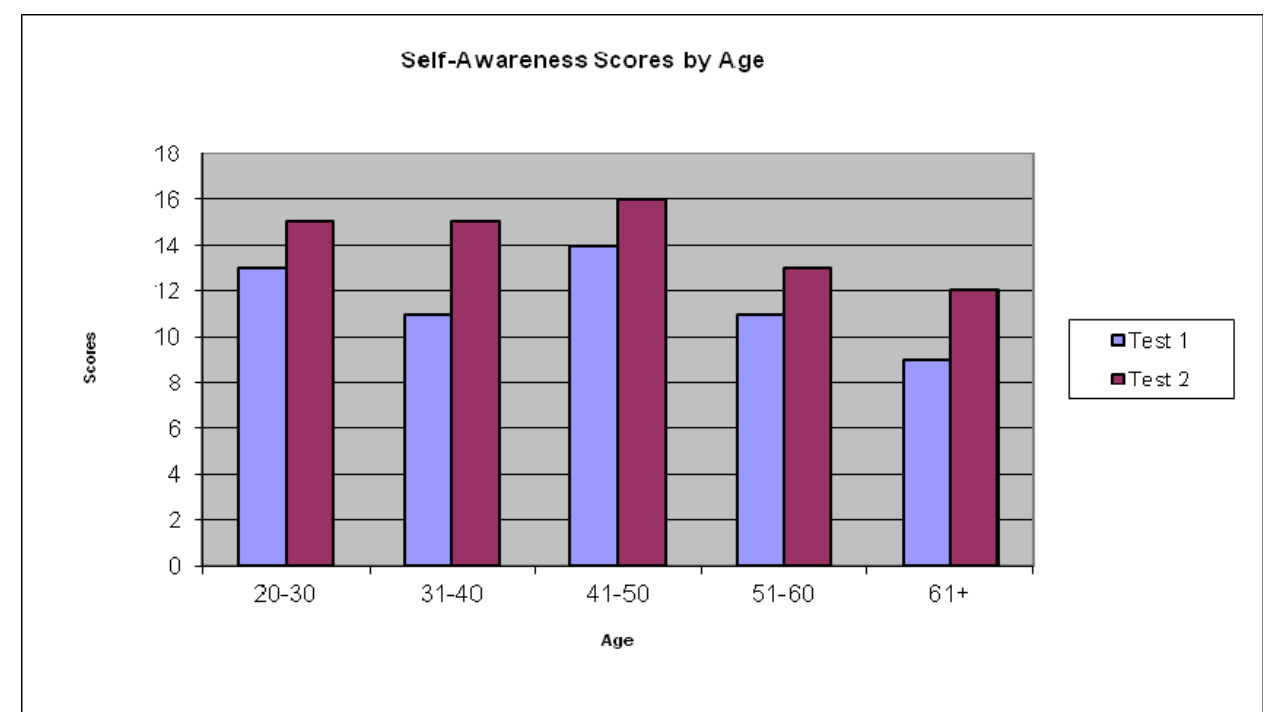

Figure 2. Data illustrating self-awareness scores by age over two-time periods with age group 31-40 showing biggest improvement 


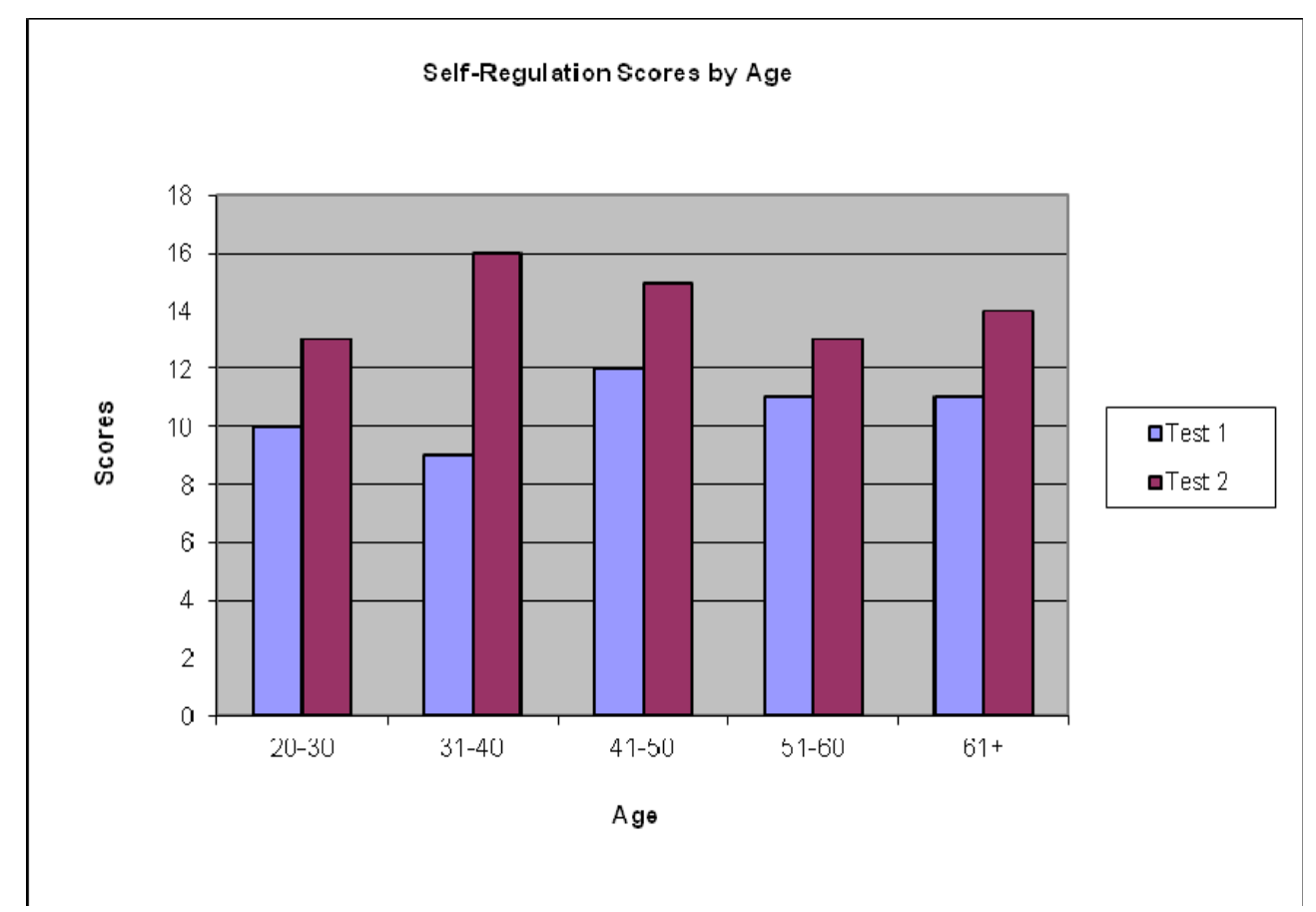

Figure 3. Data illustrating self-regulation scores by age over two-time periods with biggest improvement between age group 31-40

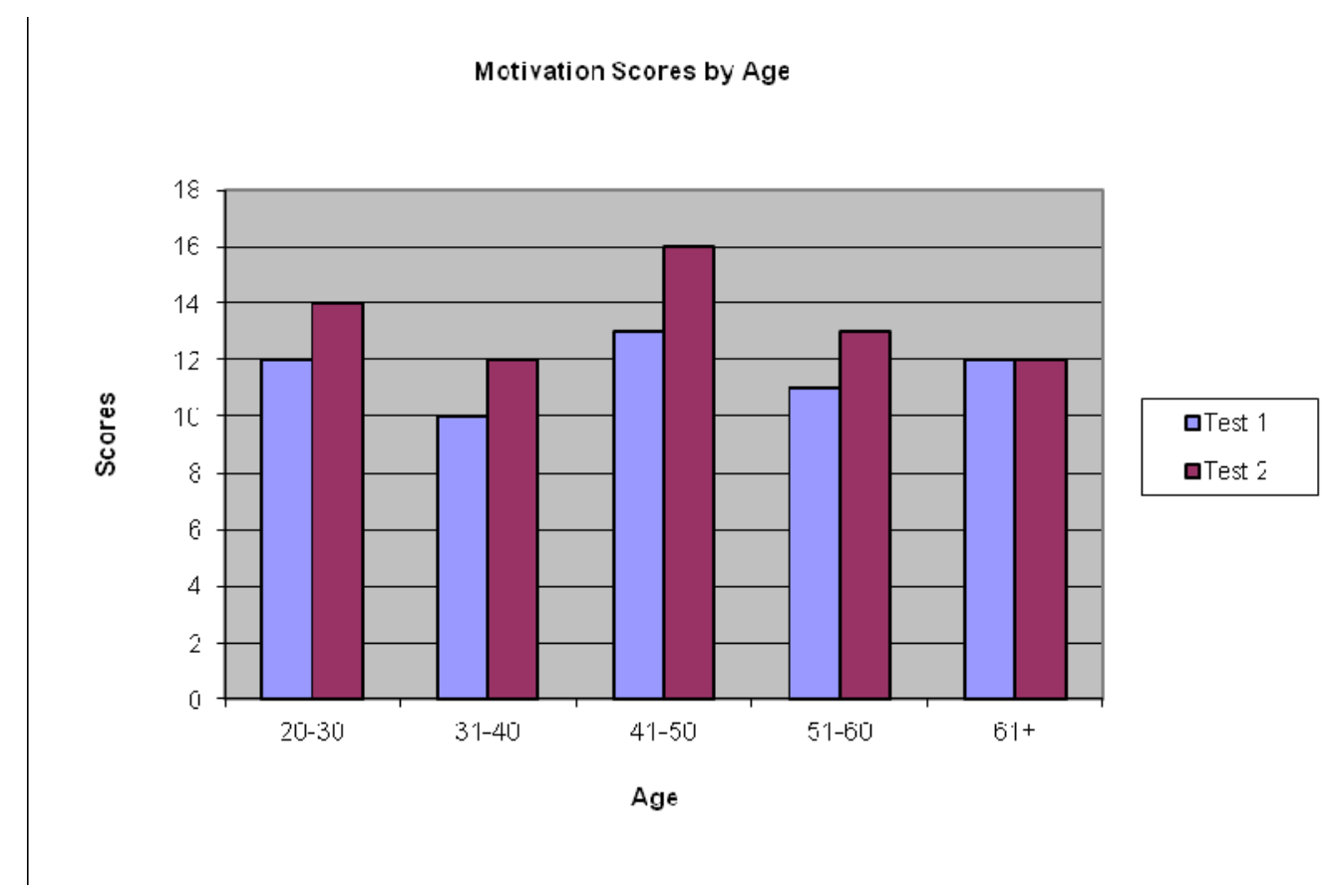

Figure 4. Data illustrating motivation scores by age over two-time periods with age group 41-50 showing biggest improvement 


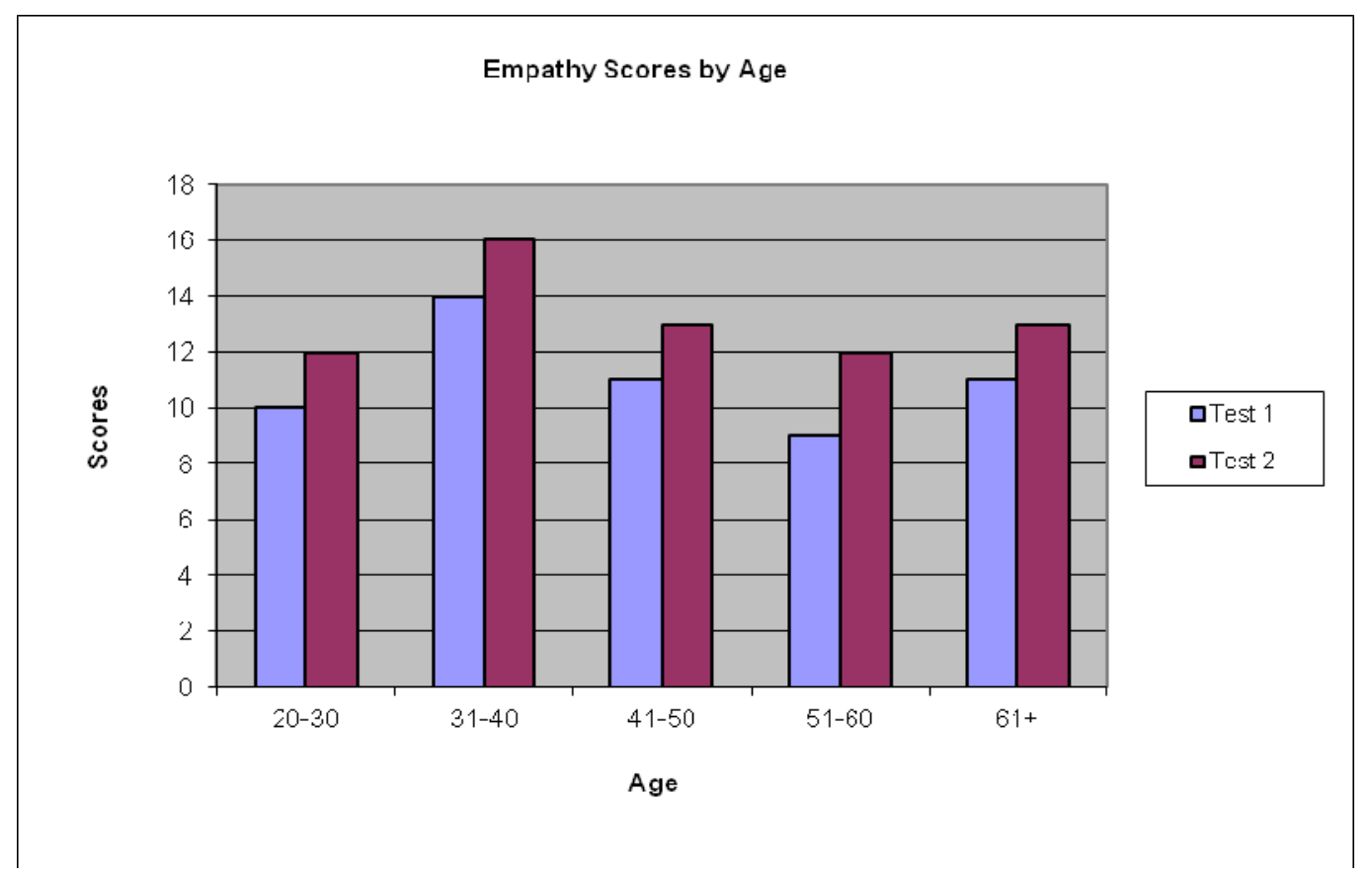

Figure 5. Data illustrating empathy scores by age over two-time periods with age group 51-60 showing biggest improvement

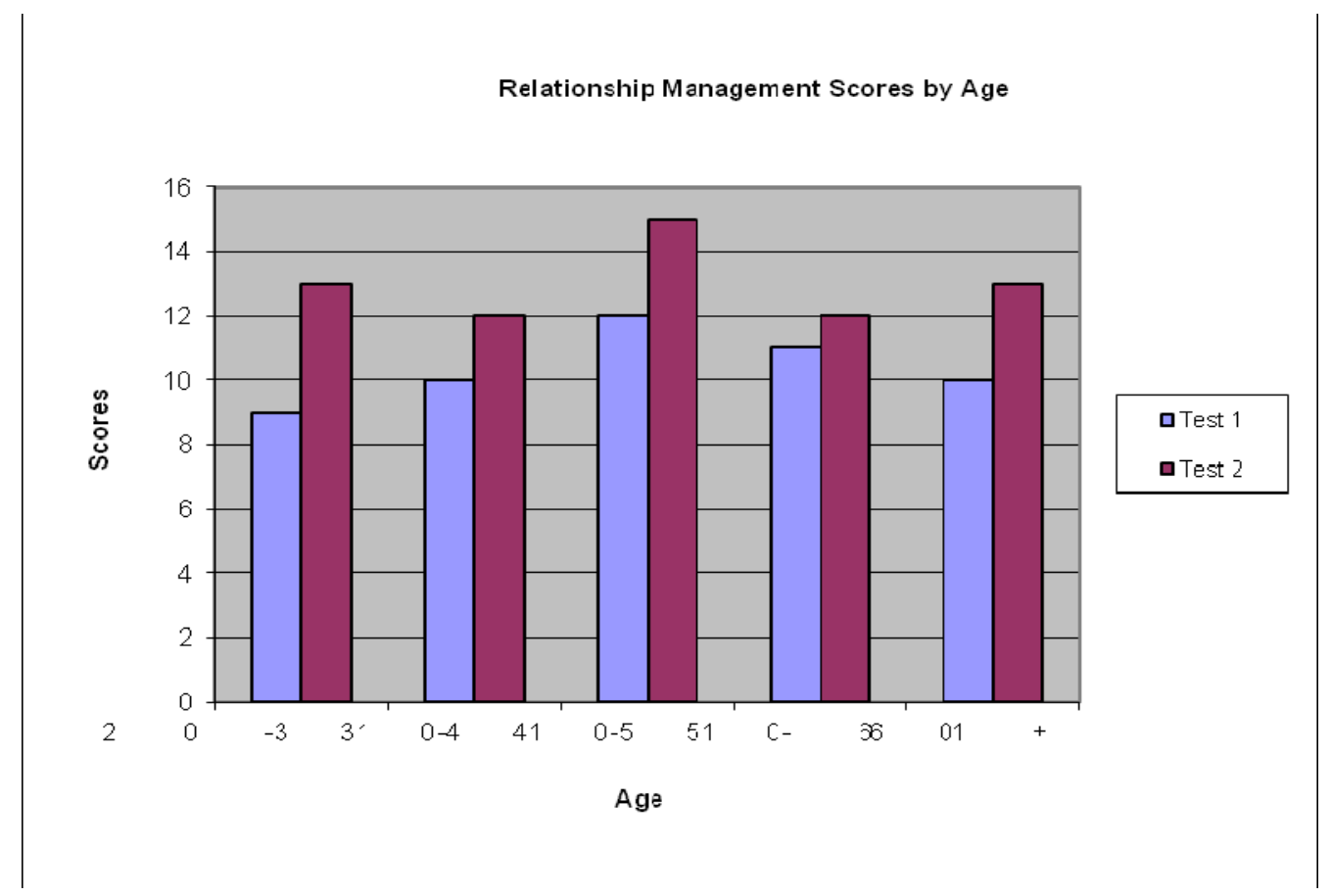

Figure 6. Data illustrating relationship management scores by age over two-time periods with age group 20-30 showing biggest improvement 


\section{Focus Group Interviews}

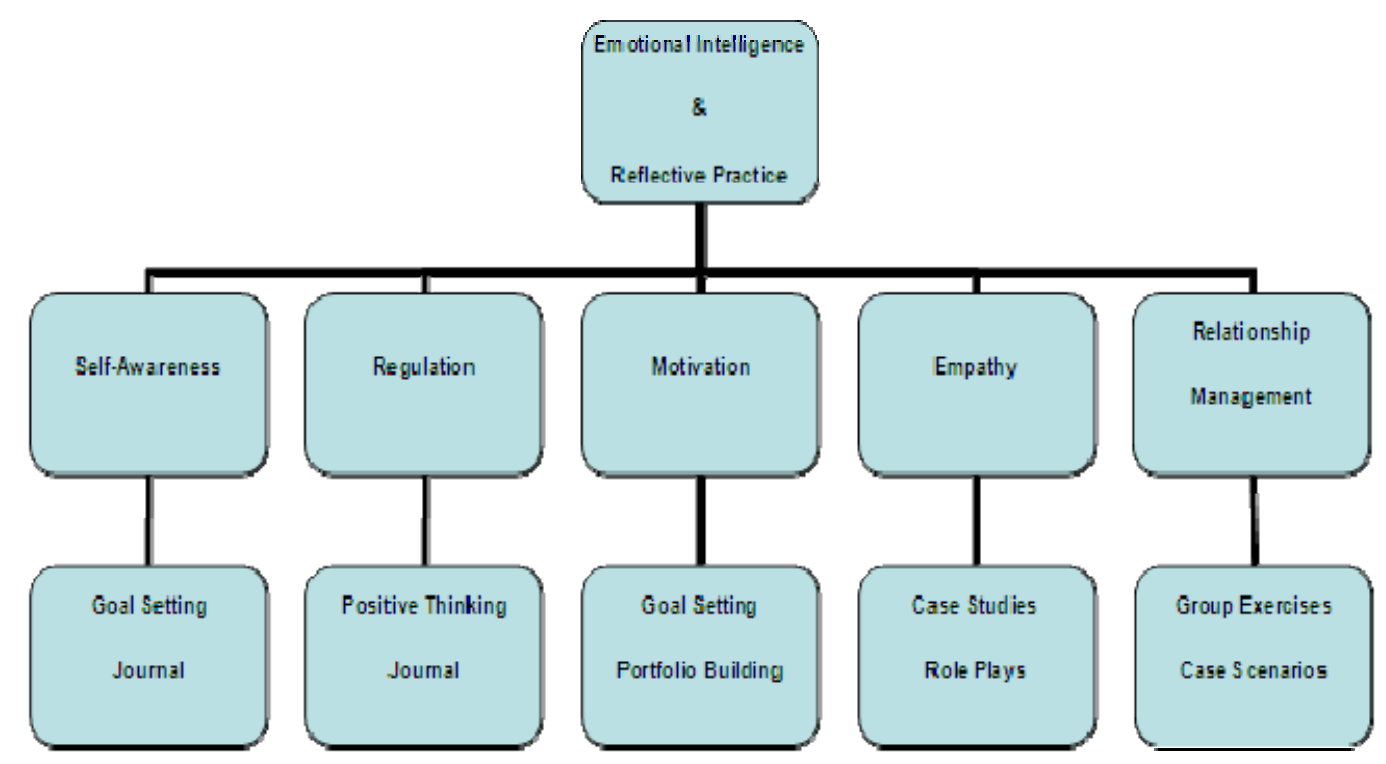

Figure 7. Illustration identifying useful strategies employed by practitioners during tutorials

\subsection{Self-Awareness}

Focus group interviews indicated that self-awareness was paramount for practitioners during tutorials possibly owing to the different range of students. During the period of investigation it was evident that practitioners utilised a range of strategies to increase levels of self-awareness. Goal setting was one strategy that was implemented by practitioners to support students with assignment completion. To supplement this further, the use of a journal enabled students to monitor and take ownership of their own progress. The common theme exhibited by practitioners was that through goal setting self-awareness was increased as direction and focus were promoted. Given that one aim of this investigation was to explore how reflective practice supported tutorials it was suggestive that goal setting is useful for signposting strengths and areas to improve to help increase self-awareness.

\subsection{Regulation of Emotion}

Focus group interviews evidenced that practitioners identified with different strategies to help regulate emotion. Practitioners felt that they attempted to reflect on their own emotions and developed ways to combat negative emotion. For example, thinking positively arguably enhances performance levels and increases work productivity (Harter, Schmidt \& Keyes, 2003). It was also identified that the use of a journal enabled opportunities to be identified in dealing with students during tutorials. To this degree, maintaining a journal enabled practitioners to become more aware of the impact of student emotions. Arguably, practitioners benefitted from incorporating a journal within tutorials as it enhanced direction and focus to regulate and balance student emotions. It could also be suggested that journal use enabled practitioners to reflect on performance and seek ways to improve and enhance productivity (Paton, 2008) amongst their students.

\subsection{Motivation}

Through focus groups it was established that engagement increased motivation levels. For example, practitioners identified a range of motivation strategies to support students in tutorial settings. One common strategy to increase motivation levels was the use of specific process goals. As goals were continuously reviewed this maintained motivation levels to help monitor progress and action plan for future weeks. It also enabled practitioners to develop plans and analyse their purpose and amend accordingly. A consequence of goal setting was that it enabled practitioners and students to agree on set action plans and areas to improve.

\subsection{Empathy}

Practitioners agreed that empathy plays an important role when dealing with students. It was also important for students to increase their empathy levels and to this degree practitioners incorporated case studies. One suggested example of a case study emanated towards working with a disabled child to assess how this individual 
could be incorporated into an able bodied practical session. In enhancing own empathy levels practitioners attempted to reflect on their own actions during the three-week period allowing strategies to be developed to identify future ways forward. Conversely, practitioners also tasked students to reflect on actions within tutorial settings and this arguably led to increased empathy levels. Responses highlighted that students emphasised with the situation from which actions were discussed.

\subsection{Relationship Management}

It was identified by practitioners that establishing and maintaining good relationships with colleagues was imperative. These relationships were further enhanced as staff development workshops allowed practitioners to share best practices. Based on these exercises some practitioners took it upon themselves to use relevant exercises within their tutorial groups. For example, exercises were used to identify what consists of good management and leadership. Thus, students were instructed into role-play situations where they became the practitioner and worked alongside peers to become aware of managing relationships. Managing relationships effectively was purposeful for students in tutorials because it made them appreciate life experiences. In some cases practitioners built on each exercise that was carried out through needs analysis enhancing their ability to reflect and identify future ways forward. Each exercise allowed a needs analysis to be formed from which students found future ways forward and reflection easier through identification.

\section{Discussion}

The purpose of this paper was to explore the nature of reflective practice and emotional intelligence in tutorial settings. This discussion will focus on overall emotional intelligence scores and the differences compared to age for each sub-component. Thus, the aim of this discussion will focus on the relationship between reflective practice and emotional intelligence to value its purpose in tutorial settings. In addition, recommendations will be proposed to support practitioners in supporting students. Limitations of the present investigation and future recommendations will be provided.

It was clearly identified that the use of reflective practice and emotional intelligence supported practitioners during the three-week period. The use of reflective practice clearly highlighted that adaptation to previous practice and experience was evident when dealing with students and would be of benefit for future use. Practitioners who displayed higher levels of emotional intelligence were nominally experienced staff. Results highlight that enhanced emotional intelligence was the result of reflective practice and vice versa.

Salovey and Mayer (1990) contend that self-awareness relates to emotions, moods and drives. Evidence from data suggests increased emotional intelligence and use of reflective practice enabled practitioners to become more self-aware of their own actions. Through employment of the reflective blog and self-reflection exercises practitioners were also successful in enhancing student self-awareness. For example, the employment of profiling (Gee, Marsall, \& King, 2010; Newman \& Crespo, 2008) enabled practitioners to examine own self-awareness levels through identification. The evidence provides support that practitioners became aware of their own self-awareness, which also enabled increased opportunities to develop strategies to increase student self-awareness. Focus group interviews indicate that self-awareness was paramount for practitioners during tutorials possibly owing to the different ability level of students. During the period of investigation it was also evident that practitioners utilised a range of strategies to increase levels of self-awareness. For example, goal setting was implemented by practitioners to support assignment completion. To supplement this further, the introduction of a journal enabled students to monitor and take ownership of their own progress. One common theme exhibited by practitioners was that through goal setting self-awareness was increased as direction and focus were promoted. In suggesting that reflective practice is related to identifying strengths and areas to improve, the use of goal setting helped both practitioners and students to increase own self-awareness.

Research from emotional intelligence has postulated the importance of self-regulation (Salovey \& Mayer, 1990). Evidence from this investigation highlighted that self-regulation showed the highest percentage increase. To enhance self-regulation practitioners utilized a range of interventions and shared best practice amongst peers. To facilitate self-regulation in maintaining emotional balance practitioners utilized a range of strategies that included setting specific goals, participating in regular exercise, listening to music and completing short concise activities.

Maintaining and increasing motivation was a key characteristic for practitioners. Evidence suggest that motivation levels increased over the two-time periods for all age groups. Arguably, motivation levels increased as focus group interviews identified that practitioners found the use of a "priority journal" as useful. One key benefit for maintaining journals is that it enables practitioners to prioritise their own educational requirements in 
enhancing and maintaining motivation levels. Through incorporating specific goals practitioners were able to maintain their levels of motivation. Research has evidenced the use of setting goals (e.g., business (Chesney \& Locke, 1991), health (Bodenheimer \& Handley, 2009), and sport (Mellaieu Hanton \& O'Brien 2006). Indeed, the practice of setting and reaching goals has become an integral function of Further Education where continuous targets are set in relation to performance management.

One strategy employed to increase empathy levels was to introduce case scenarios. Based on this practice practitioners reported that students felt they dealt with situations differently to how they would previously. The evidence from focus group interviews clearly state that empathy levels increased as a result of employing useful strategies. Gentry, Weber and Sadri (2007) suggest that empathy allows practitioners to better understand emotions of work colleagues and empathise with their needs. To this degree, enhancing empathy is important because it can allow individuals to better understand others. Empathy was enhanced over the investigative period as it provided opportunities for discussion between colleagues and the completion of reflective practice supported the process. For example, through focus group interviews it was identified that empathy was enhanced as practitioners started to take notice of both positive and negative influences during tutorials.

Managing relationships in the workplace are vital as it allows for productivity and sharing of best practices. To increase relationship management two different but very effective approaches were utilised by practitioners. In tutorial settings, there was constant use of team building exercises and working with others to solve problems. This engaged and prompted students to develop and manage working relationships between themselves and was facilitated by the practitioner. This is related to good practice, as practitioners are encouraged to adapt to different teaching styles in order to meet student learning needs. In relation to working with colleagues, practitioners engaged in practices related to staff development within the workplace over the academic year. Staff development enabled practitioners to engage in reflective practice as it provided opportunities to identify with utilising best practice and then critically evaluate its success.

Limitations within this investigation need to be reported. This current investigation was over a limited time frame. Whilst the results clearly highlighted increases in the use of reflective practice and emotional intelligence, a lengthier investigation is proposed for the future. This contention is purposefully made, as it would enable more in depth exploration to examine relationships. Therefore, a proposed investigation would be to examine reflective practice and emotional intelligence relationships over a whole academic year to include all levels.

The purpose of this investigation was to assess the nature of reflective practice and emotional intelligence in tutorial settings. Evidence collated suggests the efficacy of emotional intelligence within the workplace (e.g., Gentry, Weber, \& Sadri, 2007) was demonstrated. One obvious way of allowing further exploration of reflective practice and emotional intelligence would be to increase staff development opportunities amongst practitioners to share best practices. In addition, curriculum designs could also be adapted to consider practices that promote reflective practices and increase emotional intelligence levels. Arguably, reflective practice and emotional intelligence are important life skills that can support performance levels. In proposing this suggestion, consideration is given to the nature of how reflective practice and emotional intelligence can endorse students in both academic and everyday life skills.

\section{Acknowledgments}

In loving memory of my mother who died whilst I was writing this paper. My mother taught me many aspects related to reflective practice and emotional intelligence. I know she will always be with me in sprit, rest in peace, mum.

\section{References}

Bodenheimer, T., \& Handley, M. A. (2009). Goal-setting for behavior change in primary care: An exploration and status report. Patient and Educational Counselling, 174-180. http://dx.doi.org/10.1016/j.pec.2009.06.001

Chesney, A., \& Locke, E. (1991). An examination of the relationship among goal difficulty, business strategies, and performance on a complex management simulation task. Academy of Management Journal, 34, 400-424. http://dx.doi.org/10.2307/256448

Chung, E. (2004). Goal Setting as a Motivational tool in Student's Self-regulated Learning. Educational Research Quarterly, 27(3), 3-9.

Coaching Leaders. (2008). The Practical EQ Emotional Intelligence Self Assessment. Coaching Leaders.

Ekebergh, M. (2007). Life-world based reflection and learning: A contribution to the reflective practise in nursing 
and nursing education. Reflective Practise, 8(3), 331-343. http://dx.doi.org/10.1080/14623940701424835

Farrell, T. S. C. (2008). Reflective Language Teaching: From Research to Practice (pp. 1-4). London: Continuum Press.

Gee, C., Marshall, J., \& King, J. (2010). Should coaches use personality assessments in the talent identification process? A 15 year predictive study on professional hockey players.

Gentry, W. A., Weber, T. J., \& Sadri, G. (2007). Empathy in the Workplace: A Tool for Effective Leadership. A Center for Creative Leadership White Paper. Retrieved from http://www.ccl.org/leadership/pdf/research/EmpathyInTheWorkplace.pdf

Gibbs, G. (1988). Learning by doing: A guide to teaching and learning methods. Oxford: Further Education Unit, Oxford Polytechnic.

Goleman, D. (2004). What Makes a Leader? Harvard Business Review, 82(1), 82-91.

Greene, J. C. (2007). Mixed methods in social inquiry. San Francisco: Jossey-Bass.

Green, M. (2001). Successful Tutoring. Good Practice for Managers and Tutors. Learning and Skills Development Agency, London.

Harter, J. K., Schmidt, F. L., \& Keyes, C. L. M. (2002). Well-being in the workplace and its relationship to business outcomes: A review of the Gallup studies. In Keyes \& Haidt (Eds.), Flourishing: the positive person and the good life (pp. 205-224). American Psychological Assn, Washington DC.

Knowles, Z., Gilbourne, D., \& Tomlinson, V. (2007). Reflections on the application of reflective practice for supervision in applied sport psychology. SPORT PSYCHOL, 21(1), 109-122.

Lee, H. J. (2005). Understanding and assessing pre-service teachers' reflective thinking. Teaching and Teacher Education, 21, 699-715. http://dx.doi.org/10.1016/j.tate.2005.05.007

Locke, E. A., \& Latham, G. P. (1990). A theory of goal setting and task performance. Englewood Cliffs, NJ: Prentice-Hall.

Mellalieu, S. D., Hanton, S., \& O'Brien, M. (2006). The effects of goal setting on rugby performance. Journal of Applied Behavior Analysis, 39, 257-261. http://dx.doi.org/10.1901/jaba.2006.36-05

Newman, J., \& Crespo, M. (2008). Performance Profiling in Tennis. ITF Coaching and Sport Science Review, 15(44), 12-16.

Salovey, P., \& Mayer, J. D. (1990). Emotional intelligence. Imagination, Cognition and Personality, 9, 185-211. http://dx.doi.org/10.2190/DUGG-P24E-52WK-6CDG

Paton, M. (2008). Reflective journals and critical thinking. In J. van Rij-Heyligers (Ed.), Intercultural Communications across University Settings-Myths and Realities "refereed proceedings of the 6th Communication Skills in University Education Conference” (pp. 201-209). Pearson Education New Zealand, Rosedale, New Zealand.

Petrides, K. V., Sangareau, Y., Furnham, A., \& Frederickson, N. (2006). Trait emotional intelligence and children's peer relations at school. Social Development, 15, 537-547. http://dx.doi.org/10.1111/j.1467-9507.2006.00355.x

Petrides, K. V., Furnham, A., \& Frederickson, N. (2004). Emotional intelligence. The Psychologist, 17, 574-577.

Perez, M. L. (2011). Teaching Emotional Self-Awareness through Inquiry-Based Education. Early Childhood Research and Practice, 13(2), 1-10.

Thelwell, R., Lane, A. M., Weston, N. J. V., \& Greenlees, I. A. (2008). Examining relationships between emotional intelligence and coaching efficacy. International Journal of Sport and Exercise Psychology, 6, 224-235. http://dx.doi.org/10.1080/1612197X.2008.9671863

Van Rooy, D. L., \& Viswesvaran, C. (2004). Emotional intelligence: A meta-analytic investigation of predictive validity and nomological net. Journal of Vocational Behavior, 65, 71-95. http://dx.doi.org/10.1016/S0001-8791(03)00076-9

Zeidner, M., Matthews, G., \& Roberts, R. D. (2004). Emotional intelligence in the workplace: A critical review. Applied Psychology: An International Review, 53, 371-399. http://dx.doi.org/10.1111/j.1464-0597.2004.00176.x 
Zimmerman, B. J., \& Martinez-Pons, M. (1986). Development of a structured interview for assessing student use of self-regulated learning strategies. American Educational Research Journal, 23, 614-628. http://dx.doi.org/10.3102/00028312023004614

\section{Appendix}

Appendix A. Emotional Intelligence Questionnaire

\begin{tabular}{|c|c|c|c|c|}
\hline \multicolumn{5}{|l|}{ Self-Awareness } \\
\hline \multicolumn{5}{|c|}{ 1. I can explain my actions: } \\
\hline Almost Never & Rarely & Sometimes & Usually & $\begin{array}{l}\text { Almost } \\
\text { Always }\end{array}$ \\
\hline 0 & 1 & 2 & 3 & 4 \\
\hline \multicolumn{5}{|c|}{ 2. Other people don't see me as I see myself: } \\
\hline Almost Never & Rarely & Sometimes & Usually & $\begin{array}{l}\text { Almost } \\
\text { Always }\end{array}$ \\
\hline 4 & 3 & 2 & 1 & 0 \\
\hline \multicolumn{5}{|c|}{ 3. I understand the feedback that others give me: } \\
\hline Almost Never & Rarely & Sometimes & Usually & $\begin{array}{l}\text { Almost } \\
\text { Always }\end{array}$ \\
\hline 0 & 1 & 2 & 3 & 4 \\
\hline \multicolumn{5}{|c|}{ 4. I can describe accurately what I am feeling: } \\
\hline Almost Never & Rarely & Sometimes & Usually & $\begin{array}{l}\text { Almost } \\
\text { Always }\end{array}$ \\
\hline 0 & 1 & 2 & 3 & 4 \\
\hline \multicolumn{5}{|c|}{ 5. Things that happen in my life makes sense to me: } \\
\hline Almost Never & Rarely & Sometimes & Usually & $\begin{array}{l}\text { Almost } \\
\text { Always }\end{array}$ \\
\hline 0 & 1 & 2 & 3 & 4 \\
\hline \multicolumn{5}{|c|}{ Self-Management } \\
\hline \multicolumn{5}{|c|}{ 1. I can stay calm, even in difficult circumstances: } \\
\hline Almost Never & Rarely & Sometimes & Usually & $\begin{array}{l}\text { Almost } \\
\text { Always }\end{array}$ \\
\hline 0 & 1 & 2 & 3 & 4 \\
\hline \multicolumn{5}{|c|}{ 2. I am prone to outbursts of anger: } \\
\hline Almost Never & Rarely & Sometimes & Usually & $\begin{array}{l}\text { Almost } \\
\text { Always }\end{array}$ \\
\hline 4 & 3 & 2 & 1 & 0 \\
\hline \multicolumn{5}{|c|}{ 3. I feel miserable: } \\
\hline Almost Never & Rarely & Sometimes & Usually & $\begin{array}{l}\text { Almost } \\
\text { Always }\end{array}$ \\
\hline 4 & 3 & 2 & 1 & 0 \\
\hline \multicolumn{5}{|c|}{ 4. I get irritated by things, other people or myself: } \\
\hline Almost Never & Rarely & Sometimes & Usually & $\begin{array}{l}\text { Almost } \\
\text { Always }\end{array}$ \\
\hline 4 & 3 & 2 & 1 & 0 \\
\hline
\end{tabular}




\begin{tabular}{|c|c|c|c|c|}
\hline \multicolumn{3}{|c|}{ 5. I get carried away and do things I regret: } & \multirow[b]{2}{*}{ Usually } & \multirow[b]{2}{*}{$\begin{array}{l}\text { Almost } \\
\text { Always }\end{array}$} \\
\hline Almost Never & Rarely & Sometimes & & \\
\hline 4 & 3 & 2 & 1 & 0 \\
\hline \multicolumn{5}{|l|}{ Motivation } \\
\hline \multicolumn{5}{|c|}{ 1. I am clear about my future goals: } \\
\hline Almost Never & Rarely & Sometimes & Usually & $\begin{array}{l}\text { Almost } \\
\text { Always }\end{array}$ \\
\hline 0 & 1 & 2 & 3 & 4 \\
\hline \multicolumn{5}{|c|}{ 2. My career is moving in the right direction: } \\
\hline Almost Never & Rarely & Sometimes & Usually & $\begin{array}{l}\text { Almost } \\
\text { Always }\end{array}$ \\
\hline 0 & 1 & 2 & 3 & 4 \\
\hline \multicolumn{5}{|c|}{ 3. I find it hard to maintain my enthusiasm what I encounter setbacks: } \\
\hline Almost Never & Rarely & Sometimes & Usually & $\begin{array}{l}\text { Almost } \\
\text { Always }\end{array}$ \\
\hline 4 & 3 & 2 & 1 & 0 \\
\hline \multicolumn{5}{|c|}{ 4. I feel excited when I think of my goals: } \\
\hline Almost Never & Rarely & Sometimes & Usually & $\begin{array}{l}\text { Almost } \\
\text { Always }\end{array}$ \\
\hline 0 & 1 & 2 & 3 & 4 \\
\hline \multicolumn{5}{|c|}{ 5. I act consistently to move towards my goals: } \\
\hline Almost Never & Rarely & Sometimes & Usually & $\begin{array}{l}\text { Almost } \\
\text { Always }\end{array}$ \\
\hline 0 & 1 & 2 & 3 & 4 \\
\hline \multicolumn{5}{|c|}{\begin{tabular}{l|l} 
Empathy & \\
\end{tabular}} \\
\hline \multicolumn{5}{|c|}{ 1. I encounter difficult people: } \\
\hline Almost Never & Rarely & Sometimes & Usually & $\begin{array}{l}\text { Almost } \\
\text { Always }\end{array}$ \\
\hline 4 & 3 & 2 & 1 & 0 \\
\hline \multicolumn{5}{|c|}{ 2. I get on well with each of my work colleagues: } \\
\hline Almost Never & Rarely & Sometimes & Usually & $\begin{array}{l}\text { Almost } \\
\text { Always }\end{array}$ \\
\hline 0 & 1 & 2 & 3 & 4 \\
\hline \multicolumn{5}{|c|}{ 3. I find it easy to "read" other people's emotions: } \\
\hline Almost Never & Rarely & Sometimes & Usually & $\begin{array}{l}\text { Almost } \\
\text { Always }\end{array}$ \\
\hline 0 & 1 & 2 & 3 & 4 \\
\hline \multicolumn{5}{|c|}{ 4. It is unpredictable how my colleagues will feel in any given situation: } \\
\hline Almost Never & Rarely & Sometimes & Usually & $\begin{array}{l}\text { Almost } \\
\text { Always }\end{array}$ \\
\hline 4 & 3 & 2 & 1 & 0 \\
\hline
\end{tabular}




\begin{tabular}{|c|c|c|c|c|}
\hline \multicolumn{5}{|c|}{ 5. People choose to work with me in preference to equally-talented colleagues: } \\
\hline Almost Never & Rarely & Sometimes & Usually & $\begin{array}{l}\text { Almost } \\
\text { Always }\end{array}$ \\
\hline 0 & 1 & 2 & 3 & 4 \\
\hline \multicolumn{5}{|c|}{ Relationship Management } \\
\hline \multicolumn{5}{|c|}{ 1. I encounter difficult people: } \\
\hline Almost Never & Rarely & Sometimes & Usually & $\begin{array}{l}\text { Almost } \\
\text { Always }\end{array}$ \\
\hline 4 & 3 & 2 & 1 & 0 \\
\hline \multicolumn{5}{|c|}{ 2. I feel comfortable talking to anyone: } \\
\hline Almost Never & Rarely & Sometimes & Usually & $\begin{array}{l}\text { Almost } \\
\text { Always }\end{array}$ \\
\hline 0 & 1 & 2 & 3 & 4 \\
\hline \multicolumn{5}{|c|}{ 3. I achieve win/win outcomes: } \\
\hline Almost Never & Rarely & Sometimes & Usually & $\begin{array}{l}\text { Almost } \\
\text { Always }\end{array}$ \\
\hline 0 & 1 & 2 & 3 & 4 \\
\hline \multicolumn{5}{|c|}{ 4. I feel uncomfortable when other people get emotional: } \\
\hline Almost Never & Rarely & Sometimes & Usually & $\begin{array}{l}\text { Almost } \\
\text { Always }\end{array}$ \\
\hline 4 & 3 & 2 & 1 & 0 \\
\hline \multicolumn{5}{|c|}{ 5. I suffer fools gladly: } \\
\hline Almost Never & Rarely & Sometimes & Usually & $\begin{array}{l}\text { Almost } \\
\text { Always }\end{array}$ \\
\hline 0 & 1 & 2 & 3 & 4 \\
\hline
\end{tabular}

Appendix B. Focus Group Interview Tool

- How and when do you use emotional intelligence and reflective practice in your teaching/tutorials?

- Explain your positive experiences with using the reflective practice journal and identified strategies for emotional intelligence?

- Describe some limitations you have had with using the reflective practice journal?

- What influences your decision to use reflective practice or understand your emotional intelligence during tutorials?

-What skills of the emotional intelligence model have you utilized most in tutorial setting?

- In deciding which skill(s) can you identify what makes you come to this decision?

- On the flip chart paper you have identified a number of skills to help enhance emotional intelligence, if you had to pick only one factor that was most important to you, what would it be?

Explain how you may feel that emotional intelligence and reflective practice can influence tutorials

In what way has the training provided over the last few weeks, included the staff development supported you as a practitioner? 


\section{Copyrights}

Copyright for this article is retained by the author(s), with first publication rights granted to the journal.

This is an open-access article distributed under the terms and conditions of the Creative Commons Attribution license (http://creativecommons.org/licenses/by/3.0/). 